\title{
Mortality of HIV-Infected Patients on Antiretroviral Therapy in a Large Public Cohort in West Africa, Burkina Faso: Frequency and Associated Factors
}

\author{
Armel Poda ${ }^{1,2^{*}}$, Arsène Hema ${ }^{2 \#}$, Jacques Zoungrana², Nongodo Firmin Kaboré2, \\ Bebar Euloges Kamboulée ${ }^{2}$ Ibrahim Soré ${ }^{2}$, Guillaume Bado ${ }^{2}$, Abdoul-Salam Ouédraogo 1,3, \\ Nicolas Meda ${ }^{4,5}$, Adrien Bruno Sawadogo ${ }^{2,3}$
}

${ }^{1}$ School of Medicine, University of Bobo Dioulasso, Bobo Dioulasso, Burkina Faso; ${ }^{2}$ Day Care Hospital for HIV-Patients of Bobo Dioulasso, Department of Infectious Diseases, Souro Sanou Teaching Hospital, Bobo Dioulasso, Burkina Faso; ${ }^{3}$ Department of Virology and Bacteriology, Souro Sanou Teaching Hospital, Bobo Dioulasso, Burkina Faso; ${ }^{4}$ School of Medicine, University of Ouagadougou, Ouagadougou, Burkina Faso; ${ }^{5}$ Muraz Center, Bobo Dioulasso, Burkina Faso.

Email: ${ }^{*}$ armelpoda@yahoo.fr

Received September $8^{\text {th }}, 2013$; revised October $8^{\text {th }}, 2013$; accepted October $15^{\text {th }}, 2013$

Copyright (C) 2013 Armel Poda et al. This is an open access article distributed under the Creative Commons Attribution License, which permits unrestricted use, distribution, and reproduction in any medium, provided the original work is properly cited.

\begin{abstract}
Background: In sub Saharan Africa, small size surveys have demonstrated early high mortality among infected patients on antiretroviral therapies (ART). Few studies have been conducted in large cohorts of HIV-patients in public health care system in West Africa. Objectives: Our study aims to determine mortality rate and its predictors in a cohort of patients on ART in a public daycare hospital in Burkina Faso. Methods: We have carried out a retrospective cohort study. All HIV-infected patients on ART between January 1st 2008 and December 31st 2011 were included in the study. Survival probability was estimated by the Kaplan-Meier method. Cox regression analysis was used to identify associated factors to mortality. Results: A total of $2243 \mathrm{HIV}$-infected patients were included in the study. During the follow-up, 218 patients representing 9.7\% were lost. About 104 patients representing 4.6\% were transferred and 1691 representing $75.4 \%$ were still in the therapeutic cohort. There were 230 death cases for a total of 4282 persons-years, $(5.4$ deaths for 100 persons-years; $95 \%$ CI: $4.8-6.3$ ). The survival probabilities after 6 months, 1 year and 2 years were $92.6 \%, 91 \%$ and $88.9 \%$ respectively. For the multivariate analysis, the following factors were independently associated to death: male gender, BMI $<18.5 \mathrm{~kg} / \mathrm{m}^{2}$, WHO stage 3 and 4, HIV-2, T-CD4 lymphocytes $<200 / \mu 1$, haemoglobin rate $<8 \mathrm{~g} / \mathrm{dl}$ and creatinine clearance $<60 \mathrm{ml} / \mathrm{m}^{2}$. Conclusions: Our study provides for the first time mortality rates and its predictors among HIV-patients on antiretroviral treatment in a large cohort in public health sector in Burkina Faso. It highlights the importance of early HIV screening to limit ART initiation at advanced HIV infection stages.
\end{abstract}

Keywords: Antiretroviral Therapy; Burkina Faso; HIV; Mortality; West Africa

\section{Introduction}

Nowadays, antiretroviral treatments (ART) do not only aim to reduce morbidity and mortality caused by HIV infection and improving infected patients' life. They also aim to prevent HIV infection [1], therefore, they have the interest of reaching universal access to ART goals (ART coverage superior or equal to $80 \%$ to those in need among infected patients). Few African countries were able to make it [2]. However, in sub Saharan Africa, the number of

${ }^{*}$ Corresponding author.

\#These authors have contributed equally to the work. patients on ART is increasing [2]. Landlocked West African country, Burkina Faso is also part of this trend with 36,248 patients on ART in December 2011 [2]. Obviously, ART have drastically reduced HIV-related morbidity and mortality [2-6]. However, one can note residual mortality among HIV-patients both in Southern and Northern countries [7]. The Souro Sanou Teaching Hospital is a public reference health centre in Burkina Faso and in West Africa for the ambulatory care to HIV-infected patients [8]. Few studies have been carried out among large cohorts in West Africa on mortality during ART in public health care system. In such conditions where patients on ART 
are increasing, we found it necessary to make investigations among the Bobo-Dioulasso cohort which includes 3089 patients on ART at the day of December 31st 2011. The objective of this study was therefore to determine mortality rates and related factors among a cohort of ART patients in Burkina Faso, West Africa.

\section{Methods}

\subsection{Study Area}

The study was conducted at the Teaching Hospital in Bobo-Dioulasso and specifically at the Day Care Hospital for HIV-patients. Bobo-Dioulasso is the second major city after Ouagadougou the capital city, in Burkina Faso

\subsection{Study Design}

We conducted a retrospective cohort study. We included all HIV patients on ART between January 1st 2008 and December 31st 2011. These patients were followed up from the initiation of the ART to June 30th 2012 (cut off point).

\subsection{Data Collection}

Data have been collected during medical examinations with ESOPE software (Epi concept). ESOPE is software for monitoring patients with HIV infection in limited resources countries. Data collected at the first visit included: socio-demographic data, medical history, WHO classification, biological and clinical examinations, data such as weight, height, etc. Samplings for biological examinations were carried out on patients with empty stomach. Examinations carried out at the first visit included haemogram, TCD4 lymphocytes counting, and creatinine checking. Data collected on ESOPE software were transferred to STATA-12 Corporation, Texas for analysis.

\subsection{Statistical Analyses}

Patients' socio-demographic, clinical and biological characteristics were described in number and percentage for qualitative variables. Quantitative variables were described through their medians and inter-quartile intervals (IQR). The Pearson chi2 test was used to compare proportions. The Student $t$ test was used to test equality between the two averages (signification threshold 5\%). To calculate the mortality rate we used at the numerator the total number of deaths that occurred during the follow up and at the denominator how long patients were followed up in the cohort from the first day of the treatment.

Survival probability was evaluated by the Kaplan-Meier method. The association between socio-demographic, clinical and immunologic factors of mortality was assessed with the Iogrank test (signification threshold $=5 \%$ ).
The effect of predictors significantly associated to the prognosis was then studied through a multivariate analysis with Cox proportional risks model.

\subsection{Ethical Issues}

This study was done in the process of routine clinical care. Collected information was kept confidential and names of patients were not included in the data collection process.

\section{Results}

\subsection{Characteristics of the Study Population}

A total of 2243 HIV infected patients were on ART between January 2008 and December 2011. These included 636 males $(28.4 \%)$ and 1607 females $(71.6 \%)$ aged between 16 to 78 years with an average age of 37 (IQR 32 45) (Table 1). Married patients represented 54.3\%, uneducated ones were $46.4 \%$ and $58.1 \%$ were unemployed.

HIV-1 was the most common infection (91.2\%) and was discovered in $59.1 \%$ of cases during an opportunistic infection. At their first medical examination $54.6 \%$ of patients were at 3 and 4 clinical stages, according to the WHO classification. The average Body Mass Index (BMI) was $20.5 \mathrm{~kg} / \mathrm{m}^{2}$ (IQR $18-23$ ) and $29.3 \%$ had a BMI $<$ 18.5 .

The pre-therapeutic biological assessment showed $7.1 \%$ of severe anaemia ( $\mathrm{hb}<8 \mathrm{~g} / \mathrm{dl}) ; 10 \%$ of kidney insufficiency (creatinine clearance $<60 \mathrm{ml} / \mathrm{m}^{2}$ ). The median number of T-CD4 lymphocytes at the initiation of the ART was 186 cells/ $\mu$ l (IQR $95-268$ ) and $6.4 \%$ of the patients had more than 350 cells $/ \mu 1$.

The median time limit between the first medical visit and the initiation of the ART was estimated to 44.0 days (IQR 21 - 206) and the median duration of the treatment was 20.0 months (IQR 9 - 35). The current medication consisted in the association of two nucleoside reverse transcriptase inhibitors (NRTIs) with a non-nucleoside reverse transcriptase inhibitor (NNRTI). The most common Anti Retroviral regimens prescribed included AZT + $3 \mathrm{TC}+\mathrm{EFV}(40.7 \%), \mathrm{AZT}+3 \mathrm{TC}+\mathrm{NVP}(31.4 \%)$.

\subsection{Cohort Follow-Up and Survival Progression}

During the follow-up, we lost 218 patients $(9.7 \%)$. Among males we lost of follow-up $4.3 \%$ of cases and among females we noted $4.8 \%$ of lost of follow-up. Around 104 (4.6\%) were transferred to different health centres. Among males, $8.9 \%$ were transferred and among females $10 \%$ were transferred $(p=0.44) .230$ deaths representing $10.3 \%$ were registered. Among males we Registered $15.4 \%$ of deaths and among females, $8.2 \%$ of 
Table 1. Basic characteristics of HIV infected patients in the cohort taking ART at the Bobo-Dioulasso day hospital between 2008 and 2011.

\begin{tabular}{|c|c|c|c|}
\hline Characteristics & $\begin{array}{c}\text { Male } \\
(n=636)\end{array}$ & $\begin{array}{c}\text { Female } \\
(\mathrm{n}=1607)\end{array}$ & $\begin{array}{c}\text { Total } \\
(\mathrm{n}=2243)\end{array}$ \\
\hline \multicolumn{4}{|l|}{ Age (years) } \\
\hline$\leq 25$ & $11(1.7)$ & $128(8.0)$ & $139(6.2)$ \\
\hline $26-35$ & $112(17.6)$ & $660(41.0)$ & $772(34.4)$ \\
\hline $36-45$ & $282(44.4)$ & $546(34.0)$ & $828(36.9)$ \\
\hline $46-55$ & $164(25.8)$ & $230(14.3)$ & $394(17.6)$ \\
\hline$>55$ & $67(10.5)$ & $43(2.7)$ & $110(4.9)$ \\
\hline Missing data & $0(0.0)$ & $0(0.0)$ & $0(0.0)$ \\
\hline \multicolumn{4}{|l|}{ Marital Status } \\
\hline Single & $111(17.5)$ & $321(20.0)$ & $432(19.3)$ \\
\hline Married & $456(71.7)$ & $762(47.4)$ & $1218(54.3)$ \\
\hline Widow & $52(8.2)$ & $397(24.7)$ & $449(20.0)$ \\
\hline Divorced & $16(2.5)$ & $127(7.9)$ & $143(6.4)$ \\
\hline Missing data & $1(0.1)$ & $0(0.0)$ & $1(0.0)$ \\
\hline \multicolumn{4}{|l|}{ Education level } \\
\hline None & $260(40.9)$ & $780(48.5)$ & $1040(46.4)$ \\
\hline Primary school & $158(24.8)$ & $454(28.3)$ & $612(27.3)$ \\
\hline Secondary and higher school & $216(34.0)$ & $372(23.2)$ & $588(26.2)$ \\
\hline Missing data & $2(0.3)$ & $1(0.0)$ & $3(0.1)$ \\
\hline \multicolumn{4}{|l|}{ Occupation } \\
\hline Unemployed & $50(7.9)$ & $1248(77.7)$ & $1298(57.9)$ \\
\hline Farmer & $117(18.4)$ & $14(0.9)$ & $131(5.8)$ \\
\hline Trader & $95(14.9)$ & $118(7.3)$ & $213(9.5)$ \\
\hline Civil servant & $263(41.4)$ & $117(7.3)$ & $380(16.9)$ \\
\hline Other & $111(17.4)$ & $110(6.9)$ & $221(9.9)$ \\
\hline Missing data & $0(0.0)$ & $0(0.0)$ & $0(0.0)$ \\
\hline \multicolumn{4}{|l|}{ AIDS screening circumstances } \\
\hline Voluntary screening & $219(34.4)$ & $587(36.5)$ & $806(35.9)$ \\
\hline Clinical suspicion & $414(65.1)$ & $912(56.7)$ & $1326(59.1)$ \\
\hline PTME & $0(0.0)$ & $102(6.4)$ & $102(4.6)$ \\
\hline Missing data & $3(0.5)$ & $6(0.4)$ & $9(0.4)$ \\
\hline \multicolumn{4}{|l|}{ BMI at the first visit $\left(\mathrm{kg} / \mathrm{m}^{2}\right)$} \\
\hline $\mathrm{BMI} \geq 18.5$ & $417(65.6)$ & $1169(72.7)$ & $1586(70.7)$ \\
\hline $\mathrm{BMI}<18.5$ & $219(34.4)$ & $438(27.3)$ & $657(29.3)$ \\
\hline Missing data & $0(0.0)$ & $0(0.0)$ & $0(0.0)$ \\
\hline
\end{tabular}

\begin{tabular}{|c|c|c|c|}
\hline \multicolumn{4}{|l|}{ WHO classification } \\
\hline Stage 1 & $112(17.6)$ & $393(24.5)$ & $505(22.5)$ \\
\hline Stage 2 & $135(21.2)$ & $405(25.2)$ & $540(24.1)$ \\
\hline Stage 3 & $294(46.2)$ & $648(40.3)$ & $942(44.0)$ \\
\hline Stage 4 & $90(14.2)$ & $147(9.1)$ & $237(10.6)$ \\
\hline Missing data & $5(0.8)$ & $14(0.9)$ & $19(0.8)$ \\
\hline \multicolumn{4}{|l|}{ Type of HIV } \\
\hline HIV1 & $562(88.4)$ & $1484(92.4)$ & $2046(91.2)$ \\
\hline HIV2 & $23(3.6)$ & $33(2.0)$ & $56(2.5)$ \\
\hline HIV $1+2$ & $51(8.0)$ & $90(5.6)$ & $141(6.3)$ \\
\hline Missing data & $0(0.0)$ & $0(0.0)$ & $0(0.0)$ \\
\hline \multicolumn{4}{|l|}{ Haemoglobin rate (g/dl) } \\
\hline Haemoglobin $\geq 8$ & $548(86.2)$ & $1370(85.2)$ & $1918(85.5)$ \\
\hline Haemoglobin $<8$ & $42(6.6)$ & $117(7.3)$ & $159(7.1)$ \\
\hline Missing data & $46(7.2)$ & $120(7.5)$ & $116(7.4)$ \\
\hline \multicolumn{4}{|c|}{ Creatinine clearance $\left(\mathbf{m l} / \mathbf{m}^{2}\right)$} \\
\hline$<60$ & $66(10.4)$ & $153(9.5)$ & $219(9.8)$ \\
\hline $60-89$ & $258(40.6)$ & $586(36.5)$ & $844(37.6)$ \\
\hline$\geq 90$ & $258(40.6)$ & $721(44.9)$ & $979(43.6)$ \\
\hline Missing data & $54(8.5)$ & $147(9.1)$ & $201(9.0)$ \\
\hline \multicolumn{4}{|l|}{ Initial CD4 (number/pl) } \\
\hline$<200 / \mu 1$ & $393(61.8)$ & $793(49.3)$ & $1186(52.9)$ \\
\hline $200-350 / \mu 1$ & $211(33.2)$ & $654(40.7)$ & $865(38.5)$ \\
\hline$>350 / \mu 1$ & $18(2.8)$ & $125(7.8)$ & $143(6.4)$ \\
\hline Missing data & $14(2.2)$ & $35(2.2)$ & $49(2.2)$ \\
\hline Therapeutics & . & & \\
\hline
\end{tabular}

Time limit between the first

examination and the initiation $35(18 ; 174) 47(21 ; 220) 44(21 ; 206)$ of the ART (day), median (IQR)

$$
\begin{array}{cccc}
\text { 2NRTI + 1NNRTI } & 541(85.1) & 1340(83.4) & 1881(83.8) \\
2 \text { NRTI + 1PI } & 93(14.6) & 263(16.4) & 356(15.9) \\
\text { 3NRTI } & 2(0.3) & 4(0.2) & 6(0.3) \\
\hline
\end{array}
$$

Categorical variables are expressed as number ( $\%$ total); continous variables are expressed as median (interquartile range).

deaths $\left(p<10^{-3}\right)$ and 1691 cases were still in the active cohort, representing $75.4 \%$. There were 230 deaths for a total of 4282 persons-years (5.4 deaths for 100 personsyears $95 \%$ CI: $4.8-6.3$ ). Most deaths, 156 out of 230, representing $68.1 \%$ occurred during the first six months following the ART initiation. Survival probability after 6 
months, 1 year and 2 years was $92.6 \%, 91 \%$ and $88.9 \%$ respectively.

\subsection{Mortality Predictors}

During the univariate analysis, socio-demographic factors associated to death included age and male gender. Death risks were two times higher in men $\left(\mathrm{p}<10^{-3}\right)$ than women (Figure 1) and 3.8 times higher among patients more than 55 years old $(p=0.002)$.

AIDS clinical suspicion at screening $\left(p<10^{-3}\right)$, severe malnutrition with a BMI $<18.5 \mathrm{~kg} / \mathrm{m}^{2}\left(p<10^{-3}\right)$, WHO 3 and 4 stages $\left(p<10^{-3}\right)$ at the initiation of the antiretroviral treatment were the clinical factors associated to death.

Biological characteristics such as HIV-2 infection, poor TCD4 lymphocytes $(<200 / \mu)$, severe anaemia $(\mathrm{hb}<$ $8 \mathrm{~g} / \mathrm{dl}$ ), creatinine clearance $<60 \mathrm{ml} / \mathrm{m}^{2}$ were significantly associated with death (Table 2).

The median time limit between the first medical visit and the starting of the ART among dead patients was comparable to that of living patients, that is, 18 versus 17 days $p=0.6$.

At the multivariate analysis the following characteristics at the initiation of the ART were independently associated with death: male gender, BMI $<18.5 \mathrm{~kg} / \mathrm{m}^{2}$, WHO stage 3 and 4, HIV-2, T-CD4 lymphocytes $<200 / \mu 1$, haemoglobin rate $<8 \mathrm{~g} / \mathrm{dl}$ and Creatinine clearance $<60$ $\mathrm{ml} / \mathrm{m}^{2}$ (Table 2).

\section{Discussion}

Our study provides for the first time both mortality rates and death risk factors among patients on ART in a cohort involving many participants in a governmental health centre in Burkina Faso and in West Africa. Longitudinal studies in West Africa were carried out either in governmental health centres or among few participants. In our retrospective cohort, we found a mortality rate of 5.4 deaths for 100 persons-years. Most death cases representing $68.1 \%$ occurred during the first six months following ART and there were 218 lost of follow-up representing $9.7 \%$. It is highly recommended that patients adhere to their treatment and follow-up visits to achieve treatment efficacy. Several studies have demonstrated that mortality in southern countries during the first six months of ART initiation is higher than in northern countries with higher number of the patients lost of follow-up $[6,7,9]$.

The mortality rate, 5.4 deaths for 100 persons-years that we found out was low compared to common rates in resources-limited countries [10]. In a meta-analysis concerning resources-limited countries like Asia, Africa, Central and South America, mortality rates varied between $2.6 \%$ and $29.7 \%$. The lowest rate was recorded in

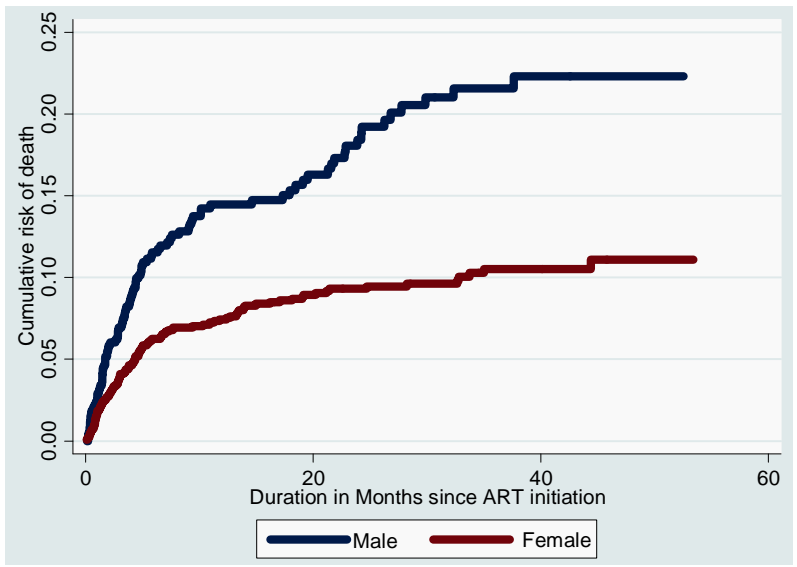

Figure 1. Risks and death curve according to gender among the HIV infected patients cohort on antiretroviral treatment at the Bobo-Dioulasso day hospital between 2008 and 2012.

a multi-regional South American cohort and the highest in sub Saharan Africa [10]. In Dakar, Senegal, on 404 adult patients from the antiretroviral treatment access initiative, the mortality rate was 12.5 deaths for 100 persons-years in the first year and decreased to 6.6 for 100 persons-years in the second year [11]. In Ivory Coast, on 10,211 adult patients taking part in the Aconda Programme, a non-governmental programme for the access to ART, the mortality rate for a period of 18 months was $11.2 \%$, the proportion of lost to follow-up was $13.6 \%$ and $85 \%$ for the survival probability with no consideration of the rate of CD4 lymphocytes [12]. In Yaounde, Cameroon, on 315 patients, a $9 \%$ mortality rate and 21.2 for 100 persons-years mortality were noted [13]. In Ethiopia, among a cohort of 1540 patients, the mortality rate varied from 15.4 for 100 persons-years in the South [14], to 2.03 (95\% CI 1.64 - 2.51) for 100 persons-years in the East [15]. However, lower mortality rates among patients on ART are often recorded in northern countries [7].

Mortality among patients on ART in countries with poor resources is often due to opportunistic infections and immune reconstitution inflammatory syndrome $[10$, $16,17]$.

In our study, patients started ART mostly at an advanced immune-depression stage due to late screening. For most patients, HIV screening was initiated on the basis of a clinical suspicion. Therefore, it was not a real screening. Patients who have discovered their HIV infection following a clinical suspicion have almost more than two times risks to die than those who have been screened when their infection was asymptomatic. This advanced immune-depression with WHO 3 and 4 stages, weak TCD4 lymphocytes rates, low haemoglobin rate and a BMI less than $18.5 \mathrm{~kg} / \mathrm{m}^{2}$ at the initiation of ART were often reported in African cohort [6,7,11,12,14,18,19] and in other southern countries [10,20-23]. Late screening 
West Africa, Burkina Faso: Frequency and Associated Factors

Table 2. Factors associated with death among an HIV infected patients cohort on ART at the Bobo-Dioulasso day hospital between 2008 and 2012.

\begin{tabular}{|c|c|c|c|c|}
\hline Independent predictors & $\mathrm{RR}$ [CI 95\%] & $\mathrm{P}$ & Adjusted RR [CI 95\%] & $\mathrm{P}$ \\
\hline \multicolumn{5}{|l|}{ Gender } \\
\hline Female & 1 & - & 1 & - \\
\hline Male & $1.98[1.52-2.56]$ & $<10^{-3}$ & $1.75[1.30-2.36]$ & $10^{-3}$ \\
\hline \multicolumn{5}{|l|}{ Age (years) } \\
\hline$\leq 25$ & 1 & - & 1 & - \\
\hline $26-35$ & $1.83[0.84-3.98]$ & 0.13 & $1.54[0.70-3.39]$ & 0.28 \\
\hline $36-45$ & $1.53[0.70-3.34]$ & 0.28 & $1.07[0.48-2.37]$ & 0.87 \\
\hline $46-55$ & $2.72[1.24-5.96]$ & 0.01 & $1.78[0.79-4.02]$ & 0.16 \\
\hline$>55$ & $3.80[1.62-8.89]$ & $2.10^{-3}$ & $1.60[0.64-3.96]$ & 0.31 \\
\hline \multicolumn{5}{|l|}{ Marital status } \\
\hline Unmarried & 1 & - & & \\
\hline Married & $0.86[0.66-1.12]$ & 0.26 & & \\
\hline \multicolumn{5}{|l|}{ Level of education } \\
\hline None & 1 & - & & \\
\hline Primary school & $0.78[0.56-1.07]$ & 0.13 & & \\
\hline Secondary and above & $0.91[0.67-1.25]$ & 0.56 & & \\
\hline \multicolumn{5}{|l|}{ Occupation } \\
\hline Unemployed & 1 & - & & \\
\hline Working & $1.15[0.89-1.49]$ & 0.29 & & \\
\hline \multicolumn{5}{|l|}{ BMI (kg/m²) } \\
\hline$\geq 18.5$ & 1 & - & 1 & - \\
\hline$<18.5$ & $3.96[3.05-5.16]$ & $<10^{-3}$ & $2.04[1.48-2.82]$ & $<10^{-3}$ \\
\hline \multicolumn{5}{|l|}{ WHO classification } \\
\hline Stage $1 \& 2$ & 1 & - & 1 & - \\
\hline Stage $3 \& 4$ & $2.65[1.97-3.56]$ & $<10^{-3}$ & $1.56[1.13-2.19]$ & $8.10^{-3}$ \\
\hline \multicolumn{5}{|l|}{ Type of HIV } \\
\hline HIV1 \& HIV $1+2$ & 1 & - & 1 & - \\
\hline HIV2 & $2.30[1.27-4.07]$ & $6.10^{-3}$ & $2.39[1.28-4.49]$ & $6.10^{-3}$ \\
\hline \multicolumn{5}{|l|}{ Haemoglobin rate (g/dl) } \\
\hline$\geq 8$ & 1 & - & 1 & - \\
\hline$<8$ & $4.21[3.02-5.87]$ & $<10^{-3}$ & $2.26[1.57-3.25]$ & $<10^{-3}$ \\
\hline \multicolumn{5}{|l|}{ Creatinine clearance $\left(\mathrm{ml} / \mathrm{m}^{2}\right)$} \\
\hline$\geq 90$ & 1 & & 1 & - \\
\hline $60-89$ & $1.50[1.09-2.07]$ & 0.01 & $0.97[0.68-1.39]$ & 0.88 \\
\hline$<60$ & $5.30[3.74-7.46]$ & $<10^{-3}$ & $2.40[1.59-3.63]$ & $<10^{-3}$ \\
\hline \multicolumn{5}{|l|}{ Initial CD4 (nb/ $\mu \mathrm{l})$} \\
\hline$\geq 200$ & 1 & - & 1 & - \\
\hline$<200$ & $3.11[2.27-4.25]$ & $10^{-3}$ & $2.30[1.62-3.23]$ & $<10^{-3}$ \\
\hline
\end{tabular}


and advanced immune-depression on ART initiation are the major causes for early mortality of patients taking ART among cohorts in countries with poor resources.

Throughout the survey we found out that men were nearly two times more exposed to death risks than women. A strong relationship between male gender and mortality when taking ART was reported in other African cohorts $[11,24,25]$. In our centre, there was no significant difference between men and women lost to follow up. In Kenya, a survey demonstrated that the rate of men in follow up programmes is lower than that of women [26]. Besides, men have a bad observance of the ART [27]. However, a survey in China showed that death risk on ART is higher when the patient does not regularly have medical visits and that women do not regularly attend checkups as men [28].

Through our results, death risk was higher among HIV-2 infected patients compared to HIV-1 and HIV-1 + 2 infected patients in a multivariate analysis. A study conducted in Ouagadougou, Burkina Faso shows that similar results are reported in non-governmental centres treating HIV infected patients [29]. In this study among patients with advanced immune-depression, there is a higher mortality rate and a lower immune restoration among HIV-2 patients compared to HIV-1 patients.

In one hand, results on immunity restoration were discovered in Gambia [30] and Ivory Coast [12]. On the other hand, in the Gambian survey mortality was higher among HIV-1 patients compared to HIV-2 and HIV-1 + 2 patients [30]. In the study carried out in Ivory Coast, there is no statistical difference in the mortality rate regarding the type of HIV [12]. In a prospective cohort survey conducted in Guinea Bissau between 1990 and 2007, 223 HIV-1 infected patients participated in the study. Those with a HIV-2 infection in addition to HIV-1 presented a slow progression towards AIDS and had a higher TCD4 lymphocytes rate [31].

We also noticed that $9.8 \%$ of patients in our cohort had a creatinine clearance $<60 \mathrm{ml} / \mathrm{m}^{2}$ at the ART initiation. In Zambia, a survey came out to the same proportions. Similarly, the authors of the study found a very close relation between the high rate of creatinine at ART initiation and death occurrence [32]. However, it is demonstrated that in countries with poor resources, where there are not always etiologic investigations in case of high creatinine, the initiation of ART improved patients' kidney function [33]. Factors associated to kidney impairment among HIV infected patients initiating ART combine diabetes, high blood pressure, heart diseases, traditional treatment and HIV-related factors such as low TCD4 lymphocytes, high viral load, WHO stage III and IV, and low BMI $[34,35]$. Nowadays according to WHO recommendations [36] tenofovir is widely used in Africa, so there are many problems with patients suffering from a kidney insufficiency when starting an ART. Though it is very efficient and well tolerated [36-38], tenofovir worsens existing kidney lesions among African cohorts [39-41].

Finally, in our study, age and level of education were not considered as risk factors. In Ethiopia, patients with a primary school education level have higher death risks than uneducated ones [14].

Our study has weaknesses: the Bobo-Dioulasso day hospital is a national reference teaching hospital with an experienced team. It provides free services including biological assessment and most opportunistic infection treatments. Our results are not representing the situation in the overall country, especially the HIV care in remote health districts where there are few practitioners and people have limited resources. However, a survey done by DWB-Holland tries to show that mortality in both vertical and integrated programmes is similar [42]. Because of the retrospective aspect of our study, data collection and the quality of some information have limitations. Some data are also missing and some factors such as viral load, opportunistic infections, death causes, and observance assessment were not taken into account. Finally, the number of those lost to follow up and the fact that we have no information on them could be a factor which does not make for the true assessment of mortality rates.

\section{Conclusion}

In our cohort, the mortality rate was 5.4 deaths per 100 person-years. Male gender, BMI $<18.5 \mathrm{~kg} / \mathrm{m}^{2}$, WHO stages 3 and 4 , the number of T-CD4 lymphocytes < $200 / \mu \mathrm{l}$, hemoglobin rate $<8 \mathrm{~g} / \mathrm{dl}$, creatinine $\geq 120 \mu \mathrm{mol} / 1$ were factors independently associated with death. This study provides for the first time, mortality rates and death risk factors for patients on ART in a cohort with a large number of participants in a government centre in Burkina Faso and West Africa. It emphasizes once again the need for screening and early initiation of ART.

\section{Acknowledgements}

The authors thank all patients of the Day Hospital of Bobo Dioulasso, the male nurses, and all non-medical staff of our department.

\section{REFERENCES}

[1] M. S. Cohen, Y. Q. Chen, M. Mc Cauley, T. Gamble, M. C. Hosseinipour, N. Kumarasamy, et al., "Prevention of HIV-1 Infection with Early Antiretroviral Therapy," New England Journal of Medicine, Vol. 365, No. 6, 2011, pp. 493-505. http://dx.doi.org/10.1056/NEJMoa1105243

[2] UNAIDS, "UNAIDS World AIDS Day Report 2012," 
2012. http://www.unaids.org/

[3] F. J. Palella, M. Deloria-Knoll, J. S. Chmiel, A. S. Moorman, K. C. Wood, A. E. Greenberg, et al., "Survival Benefit of Initiating Antiretroviral Therapy in HIV-Infected Persons in Different CD4+ Cell Strata," Annals of Internal Medicine, Vol. 138, No. 8, 2003, pp. 620-626. http://dx.doi.org/10.7326/0003-4819-138-8-200304150-0 $\underline{0007}$

[4] M. Egger, M. May, G. Chêne, A. N. Phillips, B. Ledergerber, F. Dabis, et al., "Prognosis of HIV-1-Infected Patients Starting Highly Active Antiretroviral Therapy: A Collaborative Analysis of Prospective Studies," Lancet, Vol. 360, No. 9327, 2002, pp. 119-129. http://dx.doi.org/10.1016/S0140-6736(02)09411-4

[5] D. Coetzee, K. Hildebrand, A. Boulle, G. Maartens, F. Louis, V. Labatala, et al., "Outcomes after Two Years of Providing Antiretroviral Treatment in Khayelitsha, South Africa," AIDS, Vol. 18, No. 6, 2004, pp. 887-895.

[6] S. D. Lawn, A. D. Harries, X. Anglaret, L. Myer and R. Wood, "Early Mortality among Adults Accessing Antiretroviral Treatment Programmes in Sub-Saharan Africa," AIDS, Vol. 22, No. 15, 2008, pp. 1897-1908. http://dx.doi.org/10.1097/QAD.0b013e32830007cd

[7] P. Braitstein, M. W. Brinkhof, F. Dabis, M. Schechter, A. Boulle, P. Miotti, et al., "Mortality of HIV-1-Infected Patients in the First Year of Antiretroviral Therapy: Comparison between Low-Income and High-Income Countries," Lancet, Vol. 367, No. 9513, 2006, pp. 817-824. http://dx.doi.org/10.1016/S0140-6736(06)68337-2

[8] C. Fontaine, A. Hema, E. Kamboule, J. B. Guiard-Schmid, F. X. Lescure, L. Slama, et al., "Bobo Dioulasso Teaching Hospital Day-Care Hospital: A Reference Structure for the Management of HIV Infected Patients in Burkina Faso," Vol. 40, No. 7, 2010, pp. 393-397.

[9] S. Jaffar, P. Munderi and H. Grosskurth, "Adherence to Antiretroviral Therapy in Africa: How High Is It Really?" Tropical Medicine and International, Vol. 13, No. 9, 2008, pp. 1096-1097. http://dx.doi.org/10.1111/j.1365-3156.2008.02131.x

[10] A. Gupta, G. Nadkarni, W. T. Yang, A. Chandrasekhar, N. Gupte, G. P. Bisson, et al., "Early Mortality in Adults Initiating Antiretroviral Therapy (ART) in Low- and Middle-Income Countries (LMIC): A Systematic Review and Meta-Analysis," PLoS One, Vol. 6, No. 12, 2011, Article ID: e28691. http://dx.doi.org/10.1371/journal.pone.0028691

[11] J. F. Etard, I. Ndiaye, M. Thierry-Mieg, N. F.Guèye, P. M. Guèye, I. Lanièce, et al., "Mortality and Causes of Death in Adults Receiving Highly Active Antiretroviral Therapy in Senegal: A 7-Year Cohort Study," AIDS, Vol. 20, No. 8, 2006, pp. 1181-1189. http://dx.doi.org/10.1097/01.aids.0000226959.87471.01

[12] S. Toure, B. Kouadio, C. Seyler, M. Traore, N. DakouryDogbo, J. Duvignac, et al., "Rapid Scaling-Up of Antiretroviral Therapy in 10,000 Adults in Côte d'Ivoire: 2Year Outcomes and Determinants," AIDS, Vol. 22, No. 7, 2008, pp. 873-882.

http://dx.doi.org/10.1097/QAD.0b013e3282f768f8
[13] M. Rougemont, B. E. Stoll, N. Elia and P. Ngang, "Antiretroviral Treatment Adherence and Its Determinants in Sub-Saharan Africa: A Prospective Study at Yaoundé Central Hospital, Cameroon," AIDS Research Therapy, Vol. 6, 2009, p. 21. http://dx.doi.org/10.1186/1742-6405-6-21

[14] S. Biadgilign, A. A. Reda and T. Digaffe, "Predictors of Mortality among HIV Infected Patients Taking Antiretroviral Treatment in Ethiopia: A Retrospective Cohort Study," AIDS Research Therapy, Vol. 9, No. 1, 2012, p. 15. http://dx.doi.org/10.1186/1742-6405-9-15

[15] D Jerene, A Naess and B Lindtjørn, "Antiretroviral Therapy at a District Hospital in Ethiopia Prevents Death and Tuberculosis in a Cohort of HIV Patients," AIDS Research Therapy, Vol. 3, 2006, p. 10. http://dx.doi.org/10.1186/1742-6405-3-10

[16] G. E. Poda, M. Seydi, N. M. Manga, A. B. Dieng and P. S. "Sow, Immune Reconstitution Syndrome in the Course of Antiretroviral Treatment in Senegal," Medicine et Maladies Infectieuses, Vol. 39, No. 5, 2009, pp. 350-351. http://dx.doi.org/10.1016/j.medmal.2009.01.001

[17] R. M. Novak, J. T. Richardson, K. Buchacz, J. S. Chmiel, M. D. Durham, F. J. Palella, et al., "Immune Reconstitution Inflammatory Syndrome: Incidence and Implications for Mortality," AIDS, Vol. 26, No. 6, 2012, pp. 721-731. http://dx.doi.org/10.1097/QAD.0b013e3283511e91

[18] D. M. Moore, C. T. Yiannoutsos, B. S. Musick, J. Tappero, R. Degerman, J. Campbell, et al., "Determinants of Early and Late Mortality among HIV-Infected Individuals Receiving Home-Based Antiretroviral Therapy in Rural Uganda," Journal of Acquired Immune Deficency Syndromes, Vol. 58, No. 3, 2011, pp. 289-296. http://dx.doi.org/10.1097/QAI.0b013e3182303716

[19] J. S. Stringer, I. O. Zulu, J. Levy, E. M. Stringer, A. Mwango, B. H. Chi, V. Mtonga, et al., "Rapid Scale-Up of Antiretroviral Therapy at Primary Care Sites in Zambia: Feasibility and Early Outcomes," Journal of the American Medicine Association, Vol. 296, No. 7, 2006, pp. 782-793. http://dx.doi.org/10.1001/jama.296.7.782

[20] J. Van Griensven and S. Thai, "Predictors of Immune Recovery and the Association with Late Mortality While on Antiretroviral Treatment in Cambodia," Transactions of the Royal Society of the Tropical Medicine Hygiene, Vol. 105, No. 12, 2011, pp. 694-703. http://dx.doi.org/10.1016/i.trstmh.2011.08.007

[21] A. López-Martínez , N. M. O’Brien, Y. Caro-Vega, B. Crabtree-Ramírez and J. Sierra-Madero, "Different Baseline Characteristics and Different Outcomes of HIV-Infected Patients Receiving HAART through Clinical Trials Compared with Routine Care in Mexico," Journal of Acquired Immune Deficiency Syndromes, Vol. 59, No. 2, 2012, pp. 155-160. http://dx.doi.org/10.1097/QAI.0b013e31823ff035

[22] D. Cuong do, A. Thorson , A. Sönnerborg, N. P. Hoa, N. T. Chuc, H. D. Phuc, et al., "Survival and Causes of Death among HIV-Infected Patients Starting Antiretroviral Therapy in North-Eastern Vietnam," Scandinavian Journal of Infectious Diseases, Vol. 44, No. 3, 2012, pp. 
201-208.

http://dx.doi.org/10.3109/00365548.2011.631937

[23] F. Fregonese, I. J. Collins, G. Jourdain, S. Lecoeur, T. R. Cressey, N. Ngo-Giang-Houng, et al., "Predictors of 5Year Mortality in HIV-Infected Adults Starting Highly Active Antiretroviral Therapy in Thailand," Journal of Acquired Immune Deficiency Syndromes, Vol. 60, No. 6, 2012, pp. 91-98.

http://dx.doi.org/10.1097/QAI.0b013e31824bd33f

[24] M. Bastard, M. B. Fall, I. Lanièce, B. Taverne, A. Desclaux, R. Ecochard, et al., "Revisiting Long-Term Adherence to Highly Active Antiretroviral Therapy in Senegal Using Latent Class Analysis," Journal of Acquired Immune Deficiency Syndromes, Vol. 57, No. 1, 2011, pp. 55-61. http://dx.doi.org/10.1097/QAI.0b013e318211b43b

[25] E. J. Mills, C. Bakanda, J. Birungi, K. Chan, R. S. Hogg, N. Ford, et al., "Male Gender Predicts Mortality in a Large Cohort of Patients Receiving Antiretroviral Therapy in Uganda," Journal of International AIDS Society, Vol. 14, p. 52. http://dx.doi.org/10.1186/1758-2652-14-52

[26] K. Wools-Kaloustian, S. Kimaiyo, L. Diero, A. Siika, J. Sidle, C. T. Yiannoutsos, et al., "Viability and Effectiveness of Large-Scale HIV Treatment Initiatives in Sub-Saharan Africa: Experience from Western Kenya," AIDS, Vol. 20, No. 1, 2006, pp. 41-48.

http://dx.doi.org/10.1097/01.aids.0000196177.65551.ea

[27] J. B. Nachega, M. Hislop, D. W. Dowdy, M. Lo, S. B. Omer, L. Regensberg, et al., "Adherence to Highly Active Antiretroviral Therapy Assessed by Pharmacy Claims Predicts Survival in HIV-Infected South African Adults," Journal Acquired Immune Deficiency Syndromes, Vol. 46, No. 1, 2006, pp. 78-84. http://dx.doi.org/10.1097/01.qai.0000225015.43266.46

[28] Y. Zhang, Z. Dou, K. Sun, Y. Ma, R. Y. Chen, M. Bulterys, et al., "Association between Missed Early Visits and Mortality among Patients of China National Free Antiretroviral Treatment Cohort," Journal of Acquired Immune Deficiency Syndromes, Vol. 60, No. 1, 2012, pp. 59-67. http://dx.doi.org/10.1097/QAI.0b013e31824c3d9f

[29] K. Harries, R. Zachariah, M. Manzi, P. Firmenich, R. Mathela, J. Drabo, et al., "Baseline Characteristics, Response to and Outcome of Antiretroviral Therapy among Patients with HIV-1, HIV-2 and Dual Infection in Burkina Faso," Transactions of the Royal Society of Tropical Medicine Hygiène, Vol. 104, No. 2, 2010, pp. 154-161. http://dx.doi.org/10.1016/j.trstmh.2009.08.012

[30] I. Peterson, O. Togun, T. De Silva, F. Oko, S. RowlandJones, A. Jaye, et al., "Mortality and Immunovirological Outcomes on Antiretroviral Therapy in HIV-1 and HIV2-Infected Individuals in the Gambia," AIDS, Vol. 25, No. 17, 2011, pp. 2167-2175. http://dx.doi.org/10.1097/QAD.0b013e32834c4adb

[31] J. Esbjörnsson, F. Månsson, A. Kvist, P. E. Isberg, S. Nowroozalizadeh, A. J. Biague, et al., "Inhibition of HIV-1 Disease Progression by Contemporaneous HIV-2 Infection," New England Journal of Medicine, Vol. 367, No. 3, 2012, pp. 224-232.

http://dx.doi.org/10.1056/NEJMoa1113244
[32] L. B. Mulenga, G. Kruse, S Lakhi, R. A. Cantrell, S. E. Reid, I. Zulu, et al., "Baseline Renal Insufficiency and Risk of Death among HIV-Infected Adults on Antiretroviral Therapy in Lusaka, Zambia," AIDS, Vol. 22, No. 14, 2008, pp. 1821-1827. http://dx.doi.org/10.1097/QAD.0b013e328307a051

[33] P. J. Peters, D. M. Moore, J. Mermin, J. T. Brooks, R. Downing, W. Were, et al., "Antiretroviral Therapy Improves Renal Function among HIV-Infected Ugandans," Kidney International, Vol. 74, No. 7, 2008, pp. 925-929. http://dx.doi.org/10.1038/ki.2008.305

[34] V. Jotwani, Y. Li, C. Grunfeld, A. I. Choi and M. G. Shlipak, "Risk Factors for ESRD in HIV-Infected Individuals: Traditional and HIV-Related Factors," American Journal of Kidney Diseases, Vol. 59, No. 5, 2012, pp. 628-635. http://dx.doi.org/10.1053/j.ajkd.2011.10.050

[35] L. Msango, J. A. Downs, S. E. Kalluvya, B. R. Kidenya, R. Kabangila, W. D. Johnson Jr., et al., "Renal Dysfunction among HIV-Infected Patients Starting Antiretroviral Therapy," AIDS, Vol. 25, No. 11, 2011, pp. 1421-1425. http://dx.doi.org/10.1097/QAD.0b013e328348a4b1

[36] M. W. Tang, P. J. Kanki and R. W. Shafer, "A Review of the Virological Efficacy of the 4 World Health Organization-Recommended Tenofovir-Containing Regimens for Initial HIV Therapy," Clinical Infectious Diseases, Vol. 54, No. 6, 2012, pp. 862-875. http://dx.doi.org/10.1093/cid/cir1034

[37] R. Landman, M. Poupard, M. Diallo, N. F. Ngom Gueye, N. Diakhate, B. Ndiaye et al., "Tenofovir-EmtricitabineEfavirenz in HIV-I-Infected Adults in Senegal: A 96Week Pilot Trial in Treatment-Naive Patients," Journal of International Association of Physicians in AIDS Care, Vol. 8, No. 6, 2009, pp. 379-384. http://dx.doi.org/10.1177/1545109709344352

[38] R. Scherzer, M. Estrella, Y. Li, A. I. Choi, S. G. Deeks, C. Grunfeld, et al., "Association of Tenofovir Exposure with Kidney Disease Risk in HIV Infection," AIDS, Vol. 26, No. 7, 2012, pp. 867-875. http://dx.doi.org/10.1097/QAD.0b013e328351f68f

[39] P. De Beaudrap, M. B. Diallo, R. Landman, N. F. Guèye, I. Ndiaye, A. Diouf, et al., "Changes in the Renal Function after Tenofovir-Containing Antiretroviral Therapy Initiation in a Senegalese Cohort (ANRS 1215)," AIDS Research Human Retroviruses, Vol. 26, No. 11, 2010, pp. 1221-1227. http://dx.doi.org/10.1089/aid.2009.0261

[40] R. Scherzer, M. Estrella, Y. Li, A. I. Choi, S. G. Deeks, C. Grunfeld, et al., "Association of Tenofovir Exposure with Kidney Disease Risk in HIV Infection," AIDS, Vol. 26, No. 7, 2012, pp. 867-875. http://dx.doi.org/10.1097/QAD.0b013e328351f68f

[41] A. Brennan, D. Evans, M. Maskew, S. Naicker, P. Ive, I. Sanne, et al., "Relationship between Renal Dysfunction, Nephrotoxicity and Death among HIV Adults on Tenofovir," AIDS, Vol. 25, No. 13, 2011, pp. 1603-1609. http://dx.doi.org/10.1097/QAD.0b013e32834957da

[42] J. Greig, D. P. O'Brien, N. Ford, T. Spelman, K. Sabapathy and L. Shanks, "Similar Mortality and Reduced Loss to Follow-Up in Integrated Compared with Vertical Pro- 
West Africa, Burkina Faso: Frequency and Associated Factors

grams Providing Antiretroviral Treatment in Sub-Saharan Africa," Journal of Acquired Immune Deficiebcy Syn- dromes, Vol. 59, No. 5, 2012, pp. e92-e98.

http://dx.doi.org/10.1097/QAI.0b013e31824206c7 